\title{
Insurreições urbanas e ritos públicos em fins do século XIV: as relações políticas e simbólicas nas cerimônias de punição às cidades na França medieval
}

Fabiano Fernandes*

Resumo: Enfatizaremos neste texto a discussão de algumas narrativas sobre as insurreições nas cidades de Paris e de Rouen entre 1381 e 1383, tomando como eixo principal de análise a forma como determinados ritos são apresentados nos escritos do Religioso de Saint-Denis e no texto intitulado Parte Inédita das Crônicas de Saint-Denis. O ponto de convergência entre poder real, elites urbanas e a heterogênea população estava ligado ao esforço de formalização simbólica no âmbito do cerimonial judiciário, fundamental para a conciliação que se seguia a punição às insurreições. No cerimonial judiciário, o poder dominante busca alcançar seus objetivos mediante a produção de imagens e pela manipulação de símbolos dentro de um quadro específico de interação. Logo, o esforço de sacralização da monarquia pode ser identificado no papel atribuído ao poder real em punir e agraciar de forma análoga ao supremo juiz.

Palavras-chave: Insurreições urbanas. Final da Idade Média. Sociedades urbanas.

\section{Introdução}

Os estudos de Monique Bourin, Giovanni Cherubini, Giuliano Pinto (Bourin; Cherubini, 2008) e de Cohn (2008) provocaram uma renovação na abordagem da temática das insurreições urbanas no

\footnotetext{
* Professor Adjunto II de História Medieval UNFESP. Departamento de História. Universidade Federal de São Paulo. Doutor em História Social pela UFRJ. Contato: fabfer2007@hotmail.com.
}

Anos 90, Porto Alegre, v. 21, n. 40, p. 333-361, dez. 2014 
contexto da Idade Média Tardia. No conjunto, esses estudos buscam uma abordagem metodologicamente mais sofisticada, que passa, dentre outros procedimentos, pela reavaliação do estatuto dos textos escritos de que dispomos para tratar da referida temática.

A noção de revolta popular em Cohn (2008, p. 9) pode incluir desde movimentos socialmente heterogêneos capitaneados por elites municipais contra a monarquia até movimentos compreendidos como eminentemente dos grupos subalternos contra essa mesma elite urbana. De uma maneira geral, o referido autor reputa principalmente ao amadurecimento de determinada cultura política a proliferação de diversas insurreições ao longo da segunda metade do século XIV. A perspectiva de Cohn é bem mais maleável do que a de Mollat e Wolff (1970), que defendiam que a instabilidade econômica e política do século XIV, as pestes, as fomes e as guerras explicariam por si a crise de hierarquias que teria levado às revoltas urbanas. Não desejamos descartar o peso desses fatores nas insurreições, contudo, ainda que estes elementos tenham de fato exercido um peso absolutamente decisivo na eclosão das insurreições, não explicam a forma tão plural pela qual os insurrectos exprimiram suas reivindicações. É preciso estar atento à diversidade de motivações e às formas político-culturais que estavam na base desses movimentos.

Consideramos que o significado político de cada insurreição e a pluralidade de ritos que as permeiam devem ser objeto de investigação, evitando uma abordagem teleológica, que pode tornar estéril a iniciativa de pesquisa. As práticas políticas das comunidades urbanas nem sempre assumiam um caráter diretamente associável ao que consideramos na atualidade como inerente ao campo político.

Adotamos neste texto a nomenclatura "insurreições" para evitar a associação implícita e automática que normalmente é feita da revolta como mera reação à crise econômico-social. A noção de insurreição permite discutir o fenômeno da contestação política no ambiente urbano de finais do século XIV, evitando tratar de forma homogeneizadora de um conjunto de iniciativas que estavam ligadas a contextos bem específicos. Dessa forma recuperamos a nomenclatura presente no trabalho clássico de Léon Mirot, intitulado Les Inssurections Urbaines au début de Régne de Charles VI (1380-1383) (MIROT, 1905), valorizando nessa apropriação o sentido provável 
que os contemporâneos atribuíam aos conflitos sociopolíticos. Ao estabelecer esse marco metodológico, faz-se necessário discutir os limites e as possibilidades oferecidas pelas fontes para a compreensão das insurreições.

\section{As crônicas do Religioso de Saint-Denis e a chamada Parte inédita da crônica do Religioso de Saint-Denis como fontes para estudo das cerimônias de punição às cidades}

Os ritos urbanos como canais de expressão da revolta e como meios de conciliação política são um profícuo objeto de análise para o entendimento das culturas urbanas na Idade Média tardia. A ênfase na abordagem dos ritos pode possibilitar certo entendimento das categorias políticas coevas sem incorrer em uma concepção reducionista das práticas políticas. $\mathrm{Na}$ atualidade, certa imagem dos movimentos de contestação que emergiram na sociedade burguesa do século XIX permeia o nosso senso comum, a nossa memória histórica e em certa medida alguns aspectos da historiografia sobre a temática. Os movimentos contestatórios da segunda metade do século XIV não são necessariamente uma prefiguração das revoluções liberais, tal como a historiografia oitocentista tendeu a implicitamente afirmar.

As cerimônias de punição e de conciliação, a compreensão contemporânea que se tem das mesmas e a forma como estes rituais são descritos em determinados textos serão objeto de discussão neste estudo. Logo, dentre um amplo conjunto de narrativas, escolhemos duas que são recorrentemente mencionadas nos estudos sobre a época e são abordadas muitas vezes como textos razoavelmente "fiáveis" para o entendimento do encadeamento de eventos das insurreições de Rouen ${ }^{1}$ e Paris.

Contudo, pretendemos discutir o estatuto das fontes e o que elas nos permitem identificar dos valores político-culturais da época. Logo, a partir da análise da forma como os eventos são narrados, é possível encontrar indícios dos valores que orientaram os narradores e, no limite, da cultura política de certos setores da sociedade. Afinal, como tratar fontes narrativas que pretendem estabelecer uma memória durável sobre eventos tão complexos? Quais valores 
Insurreições urbanas e ritos públicos em fins do século XIV...

podemos extrair a partir da análise crítica do contexto de produção dos textos? E, por fim, qual a relação entre os ritos urbanos de castigo e conciliação com o que certa historiografia convencionou chamar de religião real?

É fundamental explicitar as relações dos ritos, entendidos aqui enquanto práticas sociais específicas, com os símbolos, entendidos como produto das lutas políticas e das relações de força no âmbito cultural. Algumas palavras sobre esse último termo mencionado pode ajudar a esclarecer nossa perspectiva com relação ao conjunto da relação indicada.

O nosso ponto de vista é o de que um símbolo não é um repositório de significados estanques, tampouco está inserido em um sistema quase fechado sobre si próprio tal como se tende a pensar ao adotar a ideia de sistema simbólico, mas é um fenômeno cultural dinâmico que se desenvolve inserido em uma rede de informações. Essa rede é moldada por uma coletividade conflituosa de interesses, por inúmeras microações que imprimem transformações nos significados contemporaneamente partilhados. Tal como sugere a releitura de Goffman, o significado atribuído a uma determinada situação é necessariamente algo negociado, cujas expectativas de quem representa, observa e é observado fazem parte de um complexo jogo de construção da imagem social mediante a interação (GOFFMAN, 2009, p. 25-75).

Partimos da ideia de que cada conjunto de símbolos é atravessado por relações que não obedecem automaticamente a regras predeterminadas. Tal como propõe Goffman, é na interação social que é construído o significado da ação em curso e é igualmente nessa interação que o símbolo tem seu significado reapropriado (GOFFMAN, 2009, p. 25-75). A luta pela definição do significado de uma situação de interação social e de sua simbologia específica remete à noção de enquadramento de memória, pois as principais informações sobre esse processo de luta perpetuaram-se por meio de um conjunto de memórias cuidadosamente selecionadas e estruturadas, já que:

Quem diz "enquadrada" diz "trabalho de enquadramento". Todo trabalho de enquadramento de uma memória de grupo tem limites, pois ela não pode ser construída arbitrariamente. 
Esse trabalho deve satisfazer a certas exigências de justificação [...] Mas, assim como a exigência de justificação discutida acima limita a falsificação pura e simples do passado na sua reconstrução política, o trabalho permanente de reinterpretação do passado é contido por uma exigência de credibilidade que depende da coerência dos discursos sucessivos. (POLLACK, 1989, p. 6-7).

É evidente que os critérios de coerência, no caso do período convencionalmente denominado medieval, não são os nossos, e é necessário bom senso para adaptar esse conceito a um contexto em que as noções de Cristandade e comunidade são fundamentais. Contudo, do ponto de vista da monarquia, as memórias sobre as insurreições são frequentemente objeto de um verdadeiro esforço de enquadramento, que em nosso estudo é identificado a partir da análise crítica da linguagem escrita.

Entre as insurreições de 1381-1382 e a redação dos textos narrando estes conflitos, existe um espesso nível de mediação que passa pela cronologia de redação dos textos, pelo uso social pretendido para os mesmos, pela heterogeneidade do material utilizado na composição desses monumentos à memória monárquica.

O texto convencionalmente intitulado Crônica do Religioso de Saint-Denis, atribuído a Michel de Pintoin, é um testemunho altamente complexo, fundamental para a análise das insurreições urbanas de fins do século XIV e de boa parte da história política do reino de França entre 1380 e 1420. Escrito em latim, o texto do Religioso de Saint-Denis ${ }^{2}$ tem importantes antecedentes no âmbito de uma instituição, cuja relação com a memória monárquica passava por uma vasta produção historiográfica que nos dispensamos de discutir neste momento.

O Religioso de Saint-Denis, Michel de Pintoin, nascido por volta de 1349, possivelmente na Picardia, tem seus primeiros anos de vida imersos na obscuridade. Já em 1368, era monge em Saint-Denis; em junho de 1381, estava em Londres durante as insurreições que eclodiram no reino da Inglaterra; e, até pelo menos 1386, ocupou funções administrativas do temporal da abadia, que o levaram no mesmo ano a estar diretamente em contato com o rei e sua corte na

Anos 90, Porto Alegre, v. 21, n. 40, p. 333-361, dez. 2014 
Insurreições urbanas e ritos públicos em fins do século XIV...

preparação da armada - que jamais partiu - de invasão à Inglaterra, em L'Écluse. Em 1394, Pintoin era Preboste de Garenne e administrava terras e direitos de grande importância para a abadia. Por volta de 1400, com cerca de 50 anos, foi nomeado chantre de Saint-Denis (GUENÉE, 1994, p. I-LXXII) e recebeu sob seus cuidados os arquivos da instituição.

A Crônica do Religioso de Saint-Denis - que daqui por diante nomearemos CRS, indicando o livro e o respectivo volume - foi composta paulatinamente e sabe-se, por exemplo, que o relato sobre o ano de 1381 só foi escrito pelo menos após 1394. Da mesma forma, a composição dos comentários sobre o ano de 1386 só ocorreu após o ano de 1398. Presume-se que a narrativa sobre os primeiros dez anos do reinado de Carlos VI foi provavelmente redigida em período bem posterior aos eventos relatados, com cerca de dez ou quinze anos de atraso (GUENÉE, 1994, p. I-LXXII).

O livro III do volume I da reedição de 1994 trata principalmente das insurreições urbanas de 1381-1383 e é uma espécie de esforço de enquadramento da memória sobre os conflitos urbanos em uma versão amplamente favorável à monarquia. Este trecho de tão extensa crônica ${ }^{3}$ foi então elaborado em parte após as primeiras crises de loucura de Carlos VI em 1392 - que, de partida, não se imaginava que se tornariam recorrentes, progressivas e tampouco degenerativas -, mas foi concluído em período anterior à eclosão da guerra civil, a partir de cerca de $1410^{4}$. O livro III é uma peça de celebração do triunfo real, elaborada em uma época em que a memória dessas insurreições havia ligeiramente arrefecido diante da intensificação das rivalidades principescas pelo controle da administração central em Paris, disputas que se aprofundam na década de 1400. Em sua narrativa, recorrentemente o Religioso de Saint-Denis refere-se direta e indiretamente à obediência e fidelidade que deveriam nortear o comportamento dos súditos, ideias analogamente presentes em outro testemunho selecionado para discussão.

O texto tradicionalmente atribuído a Pierre de Orgemont, intitulado de forma equivocada no século XIX de Parte Inédita das Crônicas de Saint-Denis-que denominaremos daqui por diante de PICS, seguido do número da página da edição oitocentista - apresenta, de forma análoga ao de Pintoin, uma relação de estreito compromisso com

Anos 90, Porto Alegre, v. 21, n. 40, p. 333-361, dez. 2014 
a construção de uma memória monárquica para o reino. Qualquer (quaisquer) que seja(m) o(s) autor(es) deste texto, é bem provável, conforme defendido por Mirot no início do século XX (MIROT, 1905, p. VI-XIII), que tenha(m) estado presente(s) na expedição a Flandres e à punição da cidade de Paris, em 1383, e isso pode ser identificado, por exemplo, na precisão em detalhar a expedição, questão que aparece de forma bem menos pormenorizada na CRS.

A PICS, escrita em francês médio, elaborada provavelmente na segunda metade da década de 1380 foi escrita em um momento cronologicamente próximo aos eventos narrados, tendo funcionado como uma espécie de narrativa-resumo do que recentemente acontecera, para possivelmente servir como base para uma crônica que não foi concluída, hipótese apontada por Mirot em sua análise sobre o texto (MIROT, 1905, p. VI-XIII). De forma análoga ao texto de Pintoin, o texto Parte inédita das Crônicas de Saint-Denis contribuiu para o esforço de enquadramento da memória sobre as insurreições urbanas no âmbito circunscrito da memória monárquica.

O que apresentamos inicialmente como proposta é que um rito não era algo tão estruturado de partida e devemos ter igualmente cautela ao nomear o que à época aqui enfocada pode ser considerado um evento ritual. Da mesma forma a relação dos ritos urbanos com o que se convencionou chamar de religião real é algo que deve ser tratado com bastante cautela, sobretudo em um período de crises e insurreições. Do ponto de vista geral, uma entrada real é uma instância de diálogo entre o poder real e seu povo súdito, mas pode ser também parte integrante de um cerimonial de dominação política cuja relação é claramente assimétrica, simbolicamente e materialmente violenta.

A breve análise da conjuntura socioeconômica das décadas de 1360-1380 pode ajudar a entender algumas questões de fundo presentes nos conflitos e nas narrativas sobre as cerimônias de castigo às cidades que abordaremos.

No último terço do século XIV, foi comum que setores das elites urbanas manipulassem as insurreições ou as ameaças de sua ocorrência a seu favor, ora incentivando-as ou simplesmente abstendo-se de reprimi-las, ora colaborando na repressão da insurreição e negociando o perdão junto às tropas enviadas em nome do rei. 
Insurreições urbanas e ritos públicos em fins do século XIV...

Contudo, sob certas circunstâncias, as elites urbanas governantes tornaram-se também alvo da repressão real. $\mathrm{Na}$ medida em que questionavam de forma aberta o pagamento de determinadas taxas e/ou a limitação de sua autonomia, as elites urbanas também se tornavam suspeitas na ótica do poder real.

$\mathrm{Na}$ repressão à insurreição em Paris em 1383, por exemplo, o poder real suprimiu a função de preboste dos mercadores e o esboço de municipalidade que essa função representava. Além disso, primou pelo cuidado em desarmar a população e de retirar das ruas as imensas correntes que eram estendidas para dificultar o trânsito de exércitos invasores (AUTRAND, 1986, p. 75-119). Foi comum a utilização de medidas concretas e simbólicas de forma articulada como forma de explicitar a singularidade da autoridade do poder real. A prisão, a execução de revoltosos e a graça real mediante pagamento de pesadas multas faziam parte de uma das estratégias de ação, cuja relação com a simbologia da realeza pretendemos igualmente evidenciar.

A instabilidade cotidiana de jornaleiros, aprendizes e a especulação imobiliária em grandes centros como Paris tornavam a vida do "comum", como se dizia à época, bastante difícil. As oscilações de moedas, por exemplo, rentáveis para o poder real e moedeiros devido aos direitos de cunhagem - eram bastante incômodas para os proprietários urbanos e para os que baseavam seu sustento no arrendamento de terras em troca de dinheiro, como no caso de boa parte da nobreza. Por outro lado, a alternativa que era colocada à quebra da moeda era justamente o aumento de impostos indiretos que sobrecarregavam o consumo por meio da cobrança de taxas sobre circulação de mercadorias e gêneros. Tal cobrança atingia boa parte das camadas inferiores da população urbana e afetava bastante os que viviam do médio e do pequeno comércio.

A ascensão de novas elites urbanas nas décadas de 1360 a 1380 , mediante a constituição de verdadeiros clãs familiares de oficiais régios e a importância desses grupos no aparato administrativo estatal aprofundava a distinção entre um pequeno grupo de notáveis e a massa de homens que vivia do trabalho assalariado à míngua nas cidades. $\mathrm{O}$ afluxo de homens do campo para as cidades e a migração de populações intercidades em busca de oportunidades criavam, por

Anos 90, Porto Alegre, v. 21, n. 40, p. 333-361, dez. 2014 
sua vez, um clima de instabilidade sociojurídica e de insatisfação social. Situação complexa que fora agravada em consequência do conjunto dos surtos epidêmicos após 1348 e pela situação crônica de guerra que se intensificou em determinadas regiões desde 1340.

A dura reconquista de territórios no reinado de Carlos V (13641380) - intensa sobretudo no período entre 1369-1374 - foi baseada em uma estratégia de defesa sediada em fortalezas, nas guerras de cerco, na tática de terra arrasada e no abandono de boa parte do campo à própria sorte. Logo, um pequeno núcleo de homens de armas continuamente a serviço da monarquia defendeu postos estratégicos em fortalezas e cidades, evitando as batalhas abertas, deixando as longas cavalgadas inglesas simplesmente atravessarem o campo sem maiores conflitos. Simultaneamente, as fortalezas sob domínio das tropas a serviço da monarquia inglesa foram, em sua maioria, reocupadas mediante conquista ou pagamento de resgate. Dessa forma, por volta de 1380, permaneceram sob domínio do reino da Inglaterra apenas uma Aquitânia reduzida, Cherburgo e Calais, em suma, praticamente a mesma área anterior à batalha de Poitiers, em 1356. A custosa reparação de muralhas, fortalezas e a reforma de outras construções militares que resultaram na reconquista de territórios por parte da monarquia francesa foram sustentadas principalmente pela cobrança de impostos em nome do bem público do reino.

Nesse contexto de reconquista militar, a cobrança de impostos foi algo relativamente tolerado, visto que o objetivo alegado foi a limitação da violência das companhias mercenárias que atravessavam o reino, incluindo entre elas algumas que serviam a própria monarquia francesa e buscavam fortuna em sua passagem por determinada região. Mas a noção de bem público na qual se baseava formalmente a cobrança de impostos - vinculada formalmente pelos juristas, pelos oficiais régios, pelas elites municipais e pelos notáveis, de uma maneira geral, a serviço imediato do poder real - era distinta da diversidade da população citadina.

A partir de 1360, um pesado sistema foi colocado em prática. Inicialmente, a cobrança era exclusivamente indireta, cerca de 5\% sobre todas as transações e um treze avos dos vinhos e a gabela do sal. Em 1363 o clero foi submetido ao dízimo e, em primeiro de novembro do mesmo ano, na reunião dos estados de Amiens, foi 
Insurreições urbanas e ritos públicos em fins do século XIV...

concedida a cobrança de impostos diretos sobre os fogos urbanos e rurais. Uma parte das receitas recolhidas era deixada para as cidades reforçarem suas defesas e parte dos notáveis sentia-se lisonjeada por esta concessão para a manutenção da defesa local, espinha dorsal da reestruturação político-militar do reino de França nas décadas de 1360-1370 (DERMUGER, 1990, p. 56-57).

Com o refluxo momentâneo das hostilidades, por volta de 1380, as cobranças passaram a ser questionadas. No limite, a imposição de um imposto poderia ser considerada uma violação do bem público pelos setores mais agravados pelas cobranças, tais como os simples trabalhadores de ofícios, comerciantes a retalho, jornaleiros e outros simples habitantes para quem as elites impuseram o peso dos impostos indiretos e diretos.

Em 1380 os Estados Gerais convocados demandaram a abolição de todos os impostos, vista a vigência formal de tempos de paz com a Inglaterra. Segundo Favier, os burgueses de Paris, em particular, viam nesta convocação uma forma de sacudir o jugo do preboste da cidade e de alcançar um novo papel na cena política diante de um governo que consideravam enfraquecido devido às rivalidades principescas (FAVIER, 1975, p. 124-130).

Nos anos de 1380 e 1381, ocorreram conversações mútuas entre elites urbanas e poder real que se mostraram inconclusivas. As assembleias locais, durante esses dois anos, recusaram cabalmente o restabelecimento dos impostos. Em paralelo, a circulação de informações sobre os conflitos urbanos em Flandres influenciaram diversas cidades do sul e do norte do reino. Em uma árdua negociação com os príncipes da casa real - que não detalharemos neste momento -, a resistência de muitas cidades na parte norte do reino intensificou-se em nome da manutenção das antigas liberdades, pressão que culminou na abolição momentânea de todos os impostos em fins de 1381 (FAVIER, 1975, p. 124-130).

A partir dos primeiros meses de 1382, circulavam informações que indicavam que as cobranças seriam retomadas no reino de França. Em paralelo, a persistência dos conflitos em importantes cidades em Flandres, em particular com o poder condal, nominalmente vassalo da coroa francesa, contribuía para a amplificação do clima de instabilidade. 
A partir de 1382, retoma-se um ciclo de insurreição aberta nas cidades do norte e do sul do reino. De partida não era evidente que o Estado monárquico seria bem sucedido em aglutinar interesses tão divergentes, inclusive no âmbito das oligarquias urbanas cujas clivagens regionais deixamos neste momento fora de nosso escopo. Daqui por diante, concentraremos nossas considerações sobretudo nas narrativas selecionadas para discutir as revoltas das cidades de Paris e Rouen em 1381-1382, com o objetivo de identificar a forma como a memória sobre esses conflitos foi cuidadosamente enquadrada nos textos selecionados.

Segundo narrativa da PICS, o rei e os príncipes de sangue, junto com seus tios, os duques de Berry, Bourbon e Borgonha, regentes do reino, após a repressão à insurreição urbana em Flandres - derrota considerada à época por alguns setores como uma espécie de juízo de Deus, ação repressiva que se desenvolveu sobretudo durante os meses de outubro e novembro de 1382 - retornaram ao reino. A entrada na cidade de Paris a 4 de janeiro de 1383 foi a ocasião de um verdadeiro espetáculo de triunfo do rei e suas tropas. Na PICS é narrado que o rei, junto com suas tropas, divididas em três corpos de batalha:

[...] Entrou o rei em Paris com grande quantidade de homens de armas junto com ele caminhando a frente do rei [...] com o bacinete na cabeça e foram da bastide de Saint-Denis [junto ao portão com este nome], a pé, até a Igreja de Notredame, e o rei e seus tios, os duques de Berry, de Borgonha e Bourbon e outros grandes senhores foram a cavalo até as portas da igreja [...] estavam na porta o bispo e o colégio desta igreja, revestidos em suas capas, receberam o rei cantando na entrada da dita Igreja o Te deum laudamus. E vieram a pé, ao longo da Igreja, até diante da imagem, e diante da imagem fizeram suas orações, e lá o rei ofereceu a bandeira que foi levada diante dele no dia de batalha ${ }^{5}$ (PICS, 1864, p. 26, grifos nossos).

O caráter desta entrada real narrada a posteriori é polissêmico, mas dois aspectos entremeados destacam-se nesta narrativa: a liturgia da entrada real rumo à igreja e o esforço de intimidação que a este evento estava conjugado. 
A entrega no interior da igreja da bandeira com a flor-de-lis de ouro, sua simbólica relação com a monarquia e a manutenção formal da ordem vigente estavam em destaque no cerimonial partilhado pelo rei, pelos príncipes, pelos clérigos e pelos demais presentes no local que não foram expressamente indicados na narrativa sobre o evento. Havia uma cumplicidade prévia ao menos entre os príncipes de sangue real e os sacerdotes que nos autoriza a atribuir a essa situação específica de contato um caráter ritual. A bandeira da flor-de-lis, de forma análoga à auriflama, representava a relação miraculosa entre a monarquia e a Divindade, mediada hierarquicamente pela Igreja. Aqui a situação cerimonial configurou-se por meio da expectativa compartilhada pelo rei, por parte de sua comitiva e pelos homens de Igreja. Mas esta relação específica não pode ser estendida automaticamente a todos os grupos sociais de Paris, em particular aos grupos implicados nas insurreições e na recusa ao pagamento de impostos.

$\mathrm{O}$ fato de um evento poder ser ou não ser considerado um rito depende do ponto de vista de onde se pretenda tratar a questão, do grau de adesão dos envolvidos, do espaço social em que este se desenvolve e da perspectiva daquele que nos legou determinada narrativa sobre esta situação social específica.

O papel do sagrado na vitória monárquica em Flandres (e implicitamente na submissão de Paris) é ainda mais acentuado na narrativa mais tardia a CRS, ao tratar da cerimônia de entrega da bandeira da auriflama na abadia, pouco antes da entrada do rei e seus homens para castigar a cidade. Vale ressaltar que este evento é tratado na PICS de forma bastante econômica, se comparada à forma prolixa com que é referida a entrada na cidade, ou mesmo as execuções, como teremos a oportunidade de discutir nesse texto. $\mathrm{Na}$ PICS é narrado secamente que o rei teria entrado na igreja de Saint-Denis e entregue a auriflama que havia levado a Flandres, a qual teria sido colocada solenemente no altar (PICS, 1864, p. 26).

$\mathrm{Na}$ CRS, o episódio de devolução da auriflama na abadia, no burgo Saint-Denis, foi central no restabelecimento da ordem na cidade Paris. Segundo a narrativa, o agradecimento fora feito com grande devoção e gratidão, tendo em vista o papel fundamental que se considerava que a auriflama teria desempenhado em Rosebeke 
(CRS, Tomo I, Liv. III, 1994, p. 232). Logo, segundo a CRS, esse agradecimento explicitamente renovava os laços sagrados entre o patrono da abadia e a monarquia. Na ocasião em que Pierre Villiers, guardião da auriflama, teria:

[...] avançado, como havia prometido, das portas do convento até o altar dos mártires, armado de todas as peças que usara no dia do combate. Após ter depositado a oferenda sobre o altar as armas que portava, ele declarou publicamente [...] que logo após a auriflama ter sido estendida a densa neblina foi dissipada e o sol brilhou com toda sua resplandecência. [...] No dia seguinte, que era dia 10 de fevereiro, o rei, conforme sua promessa se encaminhou humildemente para a igreja, de cabeça descoberta, sem cinto, com o manto aberto dos dois lados e foi recebido pelos religiosos em procissão solene. (CRS, Tomo I, Liv. III, 1994, p. 232)

Segundo essa narrativa, por reconhecer o papel do santo patrono em sua vitória, teria o próprio rei oferecido devotamente (devotissime obtulit) dois mantos de tecido de ouro e após isso teria passado o resto do dia em estado de alegria (laetitia) junto com seus tios (CRS, Tomo I, Liv. III, 1994, p. 232). Conforme essa narrativa, este episódio teria ocorrido no meio do vagalhão do castigo à insubmissão (CRS, Tomo I, Liv. III, 1994, p. 232) e reflete implicitamente uma perspectiva muito clara quanto ao sentido da ação da realeza neste contexto.

$\mathrm{Na}$ narrativa da CRS sobre o castigo à cidade de Paris, em 1383, existe um esforço de separar hierarquicamente o espaço social da relação mosteiro/monarquia dos demais espaços da sociedade política em crise e isto se reflete na estratégia de tratar o episódio da devolução da auriflama ao altar da igreja abacial como um preâmbulo essencial ao restabelecimento do governo sobre a cidade. Esta pequena nuance narrativa reflete questões ideológicas importantes.

$\mathrm{Na}$ perspectiva presente na CRS, o poder real implicitamente tem seu prestígio acrescido na medida em que reflete mais perfeitamente uma ordem que lhe é superior, tal como a hierarquicamente mediada pelo mosteiro. Nesse sentido, a diferenciação implícita entre 
Insurreições urbanas e ritos públicos em fins do século XIV...

ofício real e a persona régia é evidenciada na narrativa de sua humilde devoção diante do pretenso apóstolo das gálias, Saint-Denis. Essa proposição fica particularmente evidente no uso de certas expressões tal como "dirigiu-se à igreja humildemente" (ad ecclesiam accedens bumiliter) (CRS, Tomo I, Liv. III, 1994, p. 232-234). A atribuição de humildade à persona regia é enfatizada na narrativa do Religioso de Saint-Denis sobre o despojamento real na forma de portar as vestes, sem cinto, com o manto aberto dos dois lados (sine corrigia et cum chlamide ab utroque aperta latere) (CRS, Tomo I, Liv. III, 1994, p. 232234). No mosteiro, segundo a narrativa, o rei tornou-se a imagem transfigurada do humilde peregrino. Neste momento, a persona real não é a majestade em triunfo, que vem castigar e punir, mas a figura humana e devota diante de seu patrono celeste. A persona régia é sutilmente distinguida do ofício real na narrativa da CRS.

À luz da narrativa da CRS sobre o castigo às revoltas de 13811382, a ideia de uma regio religio algo autônoma é questionável, ao menos no contexto específico aqui discutido. Para alguns dos mais ardorosos defensores da ordem monárquica, tal como o Religioso de Saint-Denis, a mediação dos santos e da hierarquia eclesiástica na relação com a divindade é quase indispensável. O rei, apesar de representar uma ordem que lhe é superior, é tratado quase como um simples leigo, com um estatuto especial, devido ao seu ofício, mas que diante da hierarquia eclesiástica poderia se portar, no limite extremo, como um simples peregrino.

Para muitos dos revoltosos, a possível sacralidade da persona e/ou da majestade real não era empecilho para revolta aberta contra aqueles que diziam agir em seu nome. E mesmo para alguns críticos ardorosos da insurreição, tal como a perspectiva presente na PICS, a cerimônia em curso na abadia não estava no cerne da legitimação da ação do poder real. Tampouco identificamos na PICS algo que se assemelhe ao que concebemos atualmente como uma espécie de religião real. Contudo, a auriflama devolvida à abadia por Carlos VI tinha em certos meios um peso simbólico que não deve ser subestimado.

A memória construída tendo como tema a auriflama de Saint-Denis deve ser mais bem contextualizada, a despeito de insistirmos no papel das interações na transformação do significado dos símbolos, isso não ocorre ex hibilo, visto que eventualmente no todo ou

Anos 90, Porto Alegre, v. 21, n. 40, p. 333-361, dez. 2014 
na parte alguns significados podem fazer parte dos antecedentes do complexo processo de formalização de um protocolo cerimonial ${ }^{6}$ que é considerado legítimo ao menos na ótica de uma das partes envolvidas.

Um dos primeiros indícios historicamente detectáveis da auriflama surge por volta de 1124, ocasião em que Suger, abade de Saint-Denis, convida Luis VI, na qualidade de advogado da abadia, a carregar a bandeira do santo patrono, uma peça de pano vermelha amarrada na ponta de uma lança de ouro. Na época subsequente, Luís VII (rei de 1137-1180), Felipe II (rei de 1180-1223) e São Luís (rei de 1226-1270) levaram a auriflama para as cruzadas, sem mencionar a presença deste símbolo na emblemática batalha de Bouvines, em 1214 (BEAUNE, 1991, p. 53-56).

No início do século XIII, era relativamente comum afirmar que a auriflama havia sido a bandeira conduzida por Carlos Magno em suas incursões contra os sarracenos. Supostamente o Imperador Constantino teria tido um sonho em que Carlos Magno aparecia com a bandeira anunciando que partiria para conquistar Jerusalém (BEAUNE, 1991, p. 53-56).

$\mathrm{Na}$ segunda metade do século XIV, Raoul de Presles e Jean Golein modificaram a narrativa sobre as origens da bandeira. Nesta mudança teria sido o imperador bizantino Manuel que tivera o referido sonho. Nessa nova narrativa, dizia-se que o salvador do mundo do Ocidente teria sido anunciado por um anjo. $\mathrm{O}$ imperador Manuel teria então sonhado que essa bandeira deveria ser tomada na referida abadia por Carlos Magno, que personificaria o ideal de imperador. Para outros autores, a auriflama estava diretamente relacionada a Clóvis ou ainda a Dagoberto (BEAUNE, 1991, p. 53-56). Qual fosse o sentido retrospectivo atribuído a essa bandeira, o fato é que ela, ao longo dos séculos XIII e XIV, não cessou de ganhar prestígio junto à monarquia em conjunto com o reforço do culto à memória da realeza, que tinha na abadia de Saint-Denis um dos principais sustentáculos.

Em Crecy, em 1346, a auriflama teria sido perdida no campo de batalha e substituída por uma ou diversas cópias que foram armazenadas na abadia. Segundo Beaune, foi justamente no período de 1364 a 1422, durante os reinados de Carlos V e Carlos VI, que foi 
composta uma liturgia própria de consagração das auriflamas, tendo em vista que não fora incomum ao longo do século XIV que esta insígnia simplesmente se perdesse no campo de batalha. A partir do momento em que a região de Paris e a abadia de Saint-Denis passaram para a esfera de dependência do rei da Inglaterra, por volta de 1420 , de certa forma, tanto a abadia quanto o patrono caíram em certo desprestígio junto aos que permaneceram na obediência ao futuro Carlos VII (BEAUNE, 1991, p. 53-54). Não é casual que o culto a S. Miguel tenda a crescer de importância, justamente nesse contexto (BEAUNE, 1991, p. 152-171).

Ainda que em fins do século XIV a auriflama estivesse com seu prestígio em alta, não podemos confundir este movimento de revigoramento de uma tradição monárquica e monástica no culto de Saint-Denis com a complexidade das diferentes perspectivas em conflito por ocasião das insurreições. O papel de destaque atribuído na CRS à entrega da auriflama teve de fato visibilidade para alguns poucos, mesmo levando-se em conta a muito provável circulação de notícias em Paris sobre a entrada do rei devolvendo a auriflama na abadia. Tampouco a entrega da bandeira da flor-de-lis na catedral, tal como narrado na PICS, precedida pela procissão do rei em armas junto com sua escolta, teve necessariamente uma conotação sacra para aqueles que sabiam que sua causa estava perdida. Mas é possível, a partir da análise das referidas narrativas, identificar a importância de certos aspectos políticos e simbólicos no esforço conjunto de conciliação, ao menos do ponto de vista de certa elite letrada a serviço da monarquia.

\section{Crime, castigo e conciliação: as estratégias de poder da monarquia e das elites urbanas}

A procissão real em Paris tinha provavelmente outro enfoque para boa parte dos habitantes. $\mathrm{O}$ desfile rumo à igreja catedral era $\mathrm{o}$ espetáculo de um rei em armas, montado a cavalo, com seus homens de armas a postos, que entravam em uma cidade insurrecta politicamente vencida. Era nessa massa de ferro e fúria que a bandeira da flor-de-lis estava submergida. 
A ênfase na liturgia da bandeira da flor-de-lis e da auriflama estavam presentes, respectivamente, nas narrativas da PICS e da CRS, mas não necessariamente no centro das expectativas de boa parte dos homens e mulheres que observaram à distância essas ações. Para muitos desses últimos, o que ocorrera não fora necessariamente uma cerimônia, mas um ato de simples intimidação da família real triunfante. Tampouco a quase privada cerimônia de entrega da auriflama em Saint-Denis teve necessariamente grande peso simbólico para os que não estiveram diretamente envolvidos com o cerimonial.

O ponto de convergência entre o ponto de vista do poder real, elites urbanas e a heterogênea população estava no esforço de formalização de relações no âmbito do cerimonial judiciário, fundamental no esforço de conciliação que se seguia a punição às insurreições. No cerimonial judiciário, o poder dominante busca alcançar seus objetivos mediante a produção de imagens, pela manipulação de símbolos dentro de um quadro específico de interação. A ideia básica que nutre a concepção de cerimonial judiciário é de que não é possível manter a dominação política exclusivamente pela força da coerção ou exclusivamente pela justificação racional. Tal como Balandier, compreendemos que o grande ator político comanda o "real" pelo imaginário e que de certa forma a arte do governo passa pela arte de "encenar". Da mesma forma, o ato de julgar passa por determinado grau de dramatização (BALANDIER, 1992).

$\mathrm{O}$ ato pio de agradecer a Deus a vitória, para alguns, pode ter sido o aspecto central. Para os monges de Saint-Denis e, sobretudo, para a memória cultivada nesta instituição, o rito de devolução da auriflama à abadia teve grande importância. Para muitos dos habitantes da cidade de Paris, todavia, o que provavelmente mais marcou a memória coletiva sobre esta época foram as represálias do poder real, as execuções exemplares e os esforços de conciliação após a punição.

No dia seguinte à entrada do rei com armas em Paris, foram decapitados em La Halles (principal forçado de Paris) os mercadores de panos Aubert Dampierre, Guillaume Rousseau e o ourives Henriet de Pons, que haviam sido aprisionados no Chatelet pelo preboste de Paris. Segundo a PICS, estes teriam sido aprisionados por terem sido considerados: "[...] os principais agentes e conselheiros do mal, das

Anos 90, Porto Alegre, v. 21, n. 40, p. 333-361, dez. 2014 
Insurreições urbanas e ritos públicos em fins do século XIV...

rebeliões e desobediências que foram feitas na cidade de Paris [...]" (PICS, 1864, p. 28). As execuções prosseguiram com ritmo irregular durante semanas, a justiça régia e a vingança dos príncipes seguiam uma mesma lógica de poder: a ofensa feita tinha de ser reparada e a justiça passava por certo nível de vingança-reparadora, normalmente direcionada para os setores médios e inferiores das camadas urbanas.

$\mathrm{Na}$ PICS são aludidas outras tantas execuções que se seguiram, que nos dispensamos de detalhar nesta ocasião (PICS, 1864, p. 30-31). Os notáveis executados eram, provavelmente, uma exceção calculada segundo a lógica do exemplum. A violência brutal no castigo de crimes políticos era uma atitude racionalmente calculada segundo a economia da graça. Ao pedagógico castigo, seguia-se comumente o triunfo real no perdão coletivo (PICS, 1864, p. 36).

Cessada a fase de violência física explícita, seguia-se a composição das comunidades urbanas com o poder real (e com os príncipes) que passava pelo pagamento de multas, pela perda de privilégios e pela aceitação da derrubada de símbolos que representavam a autonomia informal da municipalidade, tal como a retirada das correntes estendidas nas ruas, de portas de entrada principais e suas batentes e dos sinos das torres das igrejas (PICS, 1864, p. 34).

Em março de 1383, na cidade de Paris, após as execuções, foram iniciadas oficialmente as conversações seguidas pela conversão do castigo em multa civil. No cerimonial de conciliação, existia um roteiro político-cristão que norteava as condutas: o pecado-crime deveria ser punido mediante a vingança-reparadora (ducebant vindicandum) (CRS, Tomo I, Liv. III, 1994, p. 244), mas a expiação pública da falta deveria induzir os poderosos ao perdão e a uma nova aliança.

Podemos identificar indícios da cerimônia de conciliação, por exemplo, na cena dramaticamente narrada sobre as atitudes das mulheres dos burgueses presos diante dos príncipes da casa real, após cessar o vigor da vingança-reparadora, segundo a narrativa da CRS. Aqui, a penitência constrange a graça, pois é feita por meio da teatralização do fervor quase que religioso para com a monarquia. Nesse caso, o protocolo cerimonial foi construído de baixo para cima, utilizando práticas culturais comuns na religiosidade tradicional, de forte caráter penitencial, como forma de 
pressionar à negociação. No caso, as mulheres dos burgueses de Paris teriam rogado misericórdia no momento em que:

O ressentimento do rei e dos senhores se acalmou, e no primeiro de março, dia no qual no ano precedente havia começado a sedição, [...] Os burgueses, seguindo a ordem que haviam recebido, se reuniram com o maior número que puderam na cúria do palácio [...] Era visto no meio deles mulheres cujos maridos estavam presos; com as roupas sujas, com os cabelos desgrenhados e as mãos estendidas em direção ao rei, elas pediram humildemente (poscuerunt) misericórdia com gritos e lágrimas [...] (CRS, Tomo I, Liv. III, 1994, p. 246).

Pois, se os reis de Israel foram misericordiosos (CRS, Tomo I, Liv. III, 1994, p. 241) - tal como nas palavras atribuídas aos representantes da universidade de Paris que rogaram misericórdia ao rei -, os reis da França também deveriam ser. Determinados gestos, palavras e atitudes - que a memória escrita é avara em descrever - configuravam, na perspectiva dos que estavam sendo castigados, uma espécie de rito propiciatório da graça real.

Não existe justiça sem a graça, como não é possível pensá-la sem o exemplum (GAUVARD, 2010, p. 895-934). Esses gestos atribuídos às mulheres dos burgueses presos provavelmente são fruto de um esforço de ritualização por iniciativa de um conjunto de pessoas exteriores à cúria real. Esses gestos não foram feitos em praça pública, não parecem ter sido ensaiados ou sugeridos pelos oficiais reais. Não foram feitos às portas da igreja, tampouco às portas de uma abadia. Mas foram, segundo o Religioso de Saint-Denis, exibidos nas escadarias do palácio em resposta à convocação do rei reunido em cúria junto com seus tios e cavaleiros (CRS, Tomo I, Liv. III, 1994, p. 246). Era um pedido de clemência bem ao estilo das práticas penitenciais assimiladas na religiosidade dos leigos. Os gestos e lamentos das mulheres com vestes sujas (in sordidis vestimentis), com os cabelos desgrenhados (crinibus resolutis), o espetáculo de gritos e lágrimas (cum ingeminatis lacrimis) configuravam bem provavelmente uma espécie de pressão para a negociação (CRS, Tomo I, Liv. III, 1994, p. 246).

Anos 90, Porto Alegre, v. 21, n. 40, p. 333-361, dez. 2014 
Esta cena de penitência destacada pelo Religioso de Saint-Denis funcionava também no contexto de sua narrativa como uma mensagem sutil para a monarquia e para as elites citadinas espiritualmente próximas ao convento. Este trecho da crônica, tal como o conjunto narrativo sobre as insurreições, foram provavelmente escritos na década de 1390, época de estabilidade econômica relativa, de alívio momentâneo da ameaça inglesa nas terras centrais do domínio real, época igualmente do governo pessoal de Carlos VI e, de uma maneira geral, de certa reestruturação econômica e administrativa do reino.

O enquadramento de memória sobre as insurreições está vinculado ao relativo otimismo da década de 1390 e a forma como o Religioso de Saint-Denis concebia os atributos do poder real. Pois, do ponto de vista do religioso, os súditos deviam ao poder real obediência e sujeição; por sua vez, o rei devia aos súditos justiça firme e benevolente. Assim era possível construir um reino ideal, reflexo da Jerusalém celeste, cujas ressonâncias simbólicas estavam intrinsecamente ligadas ao patrimônio religioso-cultural da abadia de Saint-Denis e simultaneamente à importância político-simbólica da cidade de Paris.

A construção de uma imagem sutilmente favorável à cidade de Paris passa pelo reforço da ideia de que a insurreição foi principalmente produto da turba insana, e isso passava também por enfatizar determinados eventos ocorridos em outras localidades, situações consideradas pelo cronista ainda mais condenáveis do que as que aconteceram em Paris. A narrativa sobre os conflitos em Rouen, em 1381, elaborada também bem provavelmente na década de 1390, permite-nos sustentar esta perspectiva.

Segundo o Religioso de Saint-Denis, em 1382, a revolta em Rouen - que, segundo a historiografia, teria ocorrido a partir 24 de fevereiro - começou por iniciativa de mais de duzentos companheiros que trabalhavam nas artes mecânicas, conforme a narrativa, fora de senso devido talvez à embriaguez por vinho (vino forsitan temulenti), que tomaram à força um simples burguês alcunhado de o Gordo, rico mercador de panos, e o teriam colocado insolentemente mediante ameaças à cabeça de seus atos. Nesta empreitada, eles o constituíram como uma espécie de rei (regem super se ilico statuerunt), teriam entronizado o burguês em uma carroça e o conduzido pelas ruas 
sob aclamações reais barbarizantes (laudes regias barbarizantes) (CRS, Tomo I, Liv. III, 1994, p. 130). Chegando à praça do mercado, com seu "rei", teriam decretado que o povo estaria desde então livre dos impostos por meio de um arauto. A CRS classifica esta cena como ridícula, que teria feito rir os homens sábios, e a qualifica implicitamente como produto irracional da turba (CRS, Tomo I, Liv. III, 1994, p. 130). Em seguida, movidos não por audácia, mas por uma raiva furiosa (non audacia, sed ferali rabie agitati), eles teriam atacado os cobradores de impostos reais e os teriam degolado impiedosamente e, segundo a narrativa, teriam repartido entre si todos os seus haveres, como se a eles pertencessem (CRS, Tomo I, Liv. III, 1994, p. 132).

Teriam ainda, segundo a CRS, cometido crimes contra os homens de Igreja, pois teriam se dirigido a Saint-Ouen, já que estes religiosos haviam conseguido uma sentença que mantinha seus privilégios contra a cidade de Rouen. Como sugere o cronista:

[...] esses miseráveis, dignos de toda a cólera do céu, entraram à força na torre de cartas, destruíram e colocaram em pedaços os privilégios, causando uma perda irreparável, se a autoridade do rei não tivesse restabelecido os privilégios pouco depois. Impulsionados pelo mesmo extravio, e não temendo ofender a majestade real, esta gente insensata e sem armas se dirigiu ao castelo do rei para destruí-lo, mas foram rechaçados pelos que estavam dentro do castelo (CRS, Tomo I, Liv. III, 1994, p. 132).

A atitude criminosa contra a monarquia e contra a Igreja é evidenciada na narrativa referida. $\mathrm{Na} C R S$ as noções de crime e de pecado tendem ligeiramente a se fundir, a violação dos privilégios dos religiosos e do estatuto do castelo real ferem gravemente a ordem que deveria vigorar na sociedade cristã.

Contudo, afirmar cabalmente a veracidade deste relato não é necessariamente o mais importante. $\mathrm{O}$ seu valor principal reside muito mais nos valores que podemos extrair dele, sobretudo cruzando-o com o que sabemos das sociabilidades urbanas neste período.

No relato, o Religioso de Saint-Denis retém o que lhe parecia mais apropriado para atacar a memória dos revoltosos, ao apontar 
Insurreições urbanas e ritos públicos em fins do século XIV...

a atitude destes como algo inteiramente excepcional. $\mathrm{O}$ ato de carnavalização do poder que precede em Rouen o ataque à abadia e ao castelo real não é exatamente algo excepcional. O relato sobre a gente insensata (ejus gens stolida) que teria ido desarmada (inarmis) ${ }^{7}$ ao castelo e por ímpeto não teria temido ofender a majestade real (CRS, Tomo I, Liv. III, 1994, p. 132), guarda relações de parentesco com determinadas formas de sociabilidade urbana, nada inauditas, ainda que em outras circunstâncias pudessem ser vistas com certo grau de suspeição pelas autoridades.

A carnavalização do poder e das instituições não era algo que em tempos normais causasse tão grande estranheza entre os poderosos. A expressão abadessa, por exemplo, era correntemente empregada para definir a chefe das prostitutas. A expressão abadia era comumente empregada no âmbito das confraternidades de jovens, normalmente chamadas pitorescamente de abadias, principados ou reinos. Essas confrarias autonomeavam-se também como confraria da alegria, do amor, da loucura alegre e seus dignitários comumente usavam títulos de fantasia, tais como: abades, legados, cardeais, príncipes, duques; acompanhados por lugares-tenentes, porta-insígnias, priores, recebedores que dirigiam as tropas alcunhadas de monges, homens da alegria ou da infantaria (ROSSIAUD, 1980, p. 529-530). Um espelho da hierarquia formal da sociedade era encenado por meio da crítica satírica das instituições.

O processo de formação dessas confraternidades é mal conhecido e julga-se que elas se desenvolveram em paralelo às confrarias ordinárias, mas comumente não estavam adstritas a um ofício e não se configuravam como uma confraria profissional. Estas confraternidades eram únicas na cidade e adotavam uma estrutura federativa. Ao abade estavam associados dois ou quatro priores, representando os nobres, os burgueses, os artesãos e os lavradores (ROSSIAUD, 1980, p. 531-532).

Cada abadia associada tinha organização própria. No século XV, em ocasiões festivas, estas associações reuniam-se, assim como em tempos comuns, por iniciativa das autoridades que, segundo Jacques Rossiaud (ROSSIAUD, 1980, p. 531-532), cedo lograram controlar estas importantíssimas associações. No entanto, a cronologia deste processo não é facilmente identificável, tampouco o seu nível de 
sucesso em fins do século XIV. Alguns indícios indiretos de que o esforço de controle destas fluidas instituições era frágil pode ser deduzido a partir do estudo clássico de Vaultier (1965, p. 10-44) sobre as práticas culturais da época, questão que não aprofundaremos no presente texto.

As "abadias-confrarias" do século XV eram instituições que buscavam institucionalizar práticas culturais que já existiam de forma difusa no tecido urbano desde épocas recuadas. Essas instituições retiravam o essencial de seus recursos dos casamentos, das doações do conselho da cidade e, eventualmente, encarregavam-se de homenagear os notáveis diante de seus palácios (ROUSSIAUD, 1980, p. 530-532).

A lógica do "rei" entronizado em Rouen e do povo em festa rumo ao castelo após a degola dos coletores de impostos guarda, a nosso ver, uma íntima relação com estas práticas culturais de carnavalização do poder que receberam por parte das elites municipais particular esforço de controle ao longo do século XV.

As insurreições tinham suas lideranças políticas, suas formas de organização e canais de expressão cultural próprios que nem sempre obedeciam à lógica dos ofícios, como já alertara Chevalier em texto originalmente escrito na década de 80 (CHEVALIER, 1995, p. 271298). No ambiente urbano de Paris e Rouen nos anos de 1381-1383, vivia-se uma espécie de turbulência organizada, que causava uma náusea evidente nas narrativas que analisamos, que refletem o ponto de vista de ávidos partidários da ordem monárquica. A organização de uma insurreição e sua expressão política podiam assumir formas culturais que na atualidade certas pessoas mediante o senso comum teriam dificuldade de conceber como propriamente políticas, tal como na cerimônia de entronização do falso rei em Rouen.

De forma análoga, discursos que para certas pessoas atualmente soariam como algo estritamente político, tem com pano de fundo uma preocupação acentuadamente normalizadora e religiosa por parte do cronista (CRS, Tomo I, Liv. III, 1994, p. 44-47).

Segundo a CRS, os parisienses, presumivelmente nos últimos meses de 1380, tinham grande expectativa de que os subsídios fossem suspensos por ocasião da ascensão do novo rei, Carlos VI. Mas o clima era tenso, pois os jovens (Jam juniores) - ou seja, os que 
não tinham família constituída, nem cabedais próprios - reclamavam da lentidão dos anciãos (majorum), homens casados, de vida constituída, residência fixa, que tinham de fato algo a perder caso o assunto fosse levado adiante. Conforme a narrativa da CRS, a revolta (sedicione) estava prestes a eclodir, mas, no parlatório dos burgueses, o preboste dos mercadores, os vereadores e os burgueses notáveis teriam chegado a um acordo. Desta reunião teria predominado uma posição de cautela, já que o preboste teria sugerido deixar momentaneamente as coisas como estavam, para não irritar a majestade real (CRS, Tomo I, Liv. III, 1994, p. 44-47).

Mas, segundo o Religioso de Saint-Denis, da mesma forma que a palavra de um único homem teria apaziguado a multidão, a de um único grosseiro e pleno de paixão teria posto tudo a perder. Um curtidor teria aguçado a cólera do povo (plebis) através das seguintes palavras:

"não gozaremos jamais das doçuras do repouso e da comodidade? Jamais veremos cessar a cupidez sempre crescente dos senhores, que nos esmagam sem cessar de exações (abusos) múltiplos e injustos e que nos reduz a um tal esgotamento?” Compreendei vos, caros concidadãos, em qual desprezo vos viveis? Eles tomariam, se pudessem, vossa parte da luz? Eles se indignam do que vos respireis, do que vos falais, eles se indignam que vós tenhais figuras humanas e que vos encontreis com eles em lugares públicos. Eles dizem assim: por que misturar o céu com a terra? Sem dúvida esses homens a quem damos homenagem forçada, a salvação de quem nós velamos continuamente e que se nutrem de nossa substância [quibus substancias nostras impertimur $]^{8}$, que não tem outro pensamento que não seja o brilho do ouro e das joias. (CRS, Tomo I, Liv. III, 1994, p. 46, grifos nossos)

Aqui, a crítica colocada na boca do curtidor, em certa medida, reflete também a crítica do Religioso de Saint-Denis à sociedade da época em que escrevia, período de prosperidade relativa no âmbito de setores da nobreza e das oligarquias urbanas. Época de grandes festas e do encanto da cultura cavalheiresca renovada na corte dos 
grandes senhores. A cupidez (cupiditas) dos senhores - note-se que o rei não é mencionado - é o reverso da caridade, pois impede que cada um cumpra o seu papel no âmbito de um reino cristão. As exações aqui enfatizadas são aquelas que são canalizadas para o luxo dos nobres e em nada resultam para o bem da coisa pública, tal como a construção de muralhas, pagamento de exércitos e de homens de Igreja. O Religioso de Saint-Denis, a despeito de condenar a insurreição, apropria-se de sua memória como forma de expressar sua insatisfação, critica estes senhores que não pensam em outra coisa senão no brilho do ouro e das joias.

A narrativa sobre o passado recente das insurreições, qual fosse o uso posteriormente feito do texto, é um esforço de alerta. Uma mensagem para os leigos que viviam na esfera de influência espiritual da abadia e contém, em sua elaboração, a esperança de que sua mensagem chegasse de alguma forma para o mais importante dos simpáticos à instituição: o rei. Na narrativa da CRS, a ordem na sociedade cristã passava por uma justiça equilibrada em que cada um deve se conduzir segundo a lei da caridade, não retirando em excesso do outro, não se alimentando da substância alheia. Mas o perigo enfocado na CRS não é apenas a suposta insanidade da turba. A vaidade dos poderosos e suas intrigas também são vistas como uma ameaça à ordem monárquica. Aqui o "desgoverno" explicitado na narrativa sobre as insurreições tem uma função potencialmente pedagógica.

\section{Considerações finais}

Segundo o Religioso de Saint-Denis, a paz pública deveria ser reflexo da ordem celeste e caberia ao rei se colocar acima de suas próprias paixões ao punir, ao agraciar e ao se esforçar para transformar sua presença na cena urbana em um espetáculo de maior abrangência. A entrada real em uma cidade militarmente e politicamente subjugada era um evento polissêmico que culminava na conciliação por meio da ritualização da graça real. Nesse aspecto a auriflama e a bandeira de Saint-Denis desempenharam um papel relativamente modesto.

Anos 90, Porto Alegre, v. 21, n. 40, p. 333-361, dez. 2014 
A mudança de perspectiva historiográfica sobre a questão "ritual" desde a década de 20 do século XX cooperou para atribuir à ideia de rito ou de cerimônia um papel explicativo preponderante. Perspectiva presente anteriormente nos trabalhos dos historiadores alemães do direito, tal como Karl Von Amira, em fins do século $\infty$ XIX, no de Carl Schmitt, na década de 1920, em certos aspectos da ก trajetória de Kantorowicz nos EUA e nas suas derivações no âmbito (M) da historiografia norte-americana mais recente?

Contudo, a análise de uma conciliação política não deve se esgotar apenas na ênfase do papel do simbólico na constituição das relações sociais, tal como nos estudos de Gisey $(1960)^{10}$, Hanley (1983) e Jackson (1983). As relações entre o político e o simbólico são dinâmicas e complexas, sujeitas a pequenas alterações, a transformações sutis e a contradições de interpretação que devem ser objeto de história. As apropriações e os usos dos símbolos estão imersos em relações de força que o historiador deve necessariamente tentar esclarecer.

Logo, o cerne de nosso argumento é que as cerimônias de punição às cidades fazem parte de um sistema de comunicação baseado em um jogo assimétrico de negociação, em que os participantes estão frequentemente redefinindo a sua situação comunicativa. Ao interagirem estabelecem conjuntamente o significado do que está ocorrendo na própria situação de contato. Mas essa definição está imersa em relações de força muito complexas, permeadas por valores culturais que não são facilmente identificáveis.

A definição coeva de uma situação como ritual passava por uma negociação, na qual as hierarquias de poder anteriormente adquiridas tem um papel importante, mas não mecanicamente determinante. Logo, o caráter simbólico de uma cerimônia de punição é relativamente flutuante e está interligado a tramas de poder bem específicas cujos fios em boa parte se perderam para sempre. 


\section{URBAN INSURRECTIONS AND PUBLIC RITES IN LATE FOUR- TEENTH-CENTURY: THE POLITICAL AND SYMBOLICAL RELA- TIONS AT THE PUNISHMENT CEREMONIES TO THE CITIES OF MEDIEVAL FRANCE}

Abstract: We will emphasize in this text the discussion of some narratives about the uprisings in the cities of Paris and Rouen between 1381 and 1383, taking as the main axis of analysis how certain rites are presented in the writings of the religious of Saint-Denis and the text titled Inedited Part of the Chronicles of Saint-Denis. The point of convergence between the royal power, the urban elites and the heterogeneous population was connected to the effort of symbolic formalization at the judiciary ceremonial range, fundamental in the effort to reconcile the punishment that followed the uprisings. At the judiciary ceremonial the dominant power seeks to achieve its objectives through the production of images and the manipulation of symbols within a specific framework of interaction. Thus, the effort of sacralization of monarchy can be identified in the role assigned to the real power to punish and grace in a manner analogous to the supreme judge. Keywords: Urban uprisings. Late Middle Ages. Urban societies.

\section{Notas}

${ }^{1}$ Em particular a chamada Parte Inédita da Crônica de Saint-Denis é reputada por Radding (1972) como mais precisa que a chamada Crônica do Religioso de Saint-Denis. Determinados episódios dos eventos ocorridos em Rouen, tal como o de entronização de um rico burguês que analisaremos detalhadamente são considerados pelo autor como mera invenção do Religioso de Saint-Denis. A nosso ver, a verossimilhança da narrativa do Religioso de Saint-Denis está muito mais calcada nos valores que sustenta do que na precisão dos eventos que pretende narrar.

${ }^{2}$ Daqui por diante, substituiremos sempre que possível o nome de Michel de Pintoin pela expressão tradicional "Religioso de Saint-Denis".

${ }^{3}$ A "obra" é extremamente ampla. Na edição bilíngue de Bellaguet, feita de 1839 a 1852, foram necessários longos seis volumes in- $8^{\circ}$, que narram cerca de 40 anos turbulentos da história do reino de França. A edição que utilizamos de 1994, prefaciada por Guenée, é fac-simile, mas agrupa o texto integral em 3 volumes.

${ }^{4}$ É a partir de 1398 que Luís de Orleans diversifica sua ação política e inicia a luta para estender sua influência sobre a administração do estado monárquico. Os conflitos afloram sutilmente a partir de dezembro de 1401, causando então certa consternação, apesar de não ser possível para boa parte dos contemporâneos dimensionar a amplitude do embate que se anunciava, sobretudo a partir do assassinato

Anos 90, Porto Alegre, v. 21, n. 40, p. 333-361, dez. 2014 
do duque de Orleans em 1407, irmão do rei Carlos VI, por seu primo e par de França, João sem medo, duque de Borgonha. SCHNERB, Bertrand. Armagnacs et Bourguignons. La maudite guerre. 1407-1435. Paris, Perrin, 2001, p. 55-64. ${ }^{5}$ PICS, p. 26. Existe um descompasso entre as cronologias da PICS, de Pintoin e a dos historiadores. Para a PICS, o evento da entrada se deu em 11 de janeiro de 1382, na verdade 1383 de nosso calendário, pois o ano parisiense era normalmente iniciado a partir da Páscoa. Para Pintoin, a entrada do rei transcorreu em fevereiro. $\mathrm{O}$ fato do escrito do religioso ser mais tardio pode ter cooperado para certa imprecisão na cronologia.

${ }^{6}$ Compreendo por protocolo cerimonial um roteiro formal que possui um conjunto de expressões, indicações de conduta, símbolos e signos que podem se tornar em parte ou no todo uma das referências que guiam os participantes de uma determinada situação de interação. A sua formalização é produto de uma negociação assimétrica, reflete um estado provisório de relações de força, articulada formalmente por meio de linguagem escrita ou não.

${ }^{7}$ Crônica do Religioso de Saint-Denis, Tomo I, Liv. III, p. 132. Inarmis aqui provavelmente tem a conotação de "sem armas completas" para a guerra, e não exatamente de pessoas completamente desarmadas e à mercê da guarnição do castelo. Isto, todavia, não interfere na interpretação geral da questão.

${ }^{8} \mathrm{O}$ trecho original em latim foi destacado por nós entre colchetes.

${ }^{9}$ Kantorowicz, Ernst Hartwig. Laudes regiae: a study in liturgical acclamations and mediaeval ruler worship. 2. ed. California: University of California Press, 1958. Cf. Interessante balanço realizado em BOUREAU, Alain. Les cérémonies royales françaises entre performance juridique et compétence liturgique. In: Annales. Histoire, Sciences Sociales, v. 46, n. 6, p. 1253-1264, 1991.

${ }^{10} \mathrm{~A}$ base de sua perspectiva, desdobrada em diversos artigos ao longo dos anos, está em sua tese de doutoramento na UCLA, de 1954, publicada em 1960.

\section{Referências}

AUTRAND, Françoise. Charles VI. Paris: Fayard, 1986.

BEAUNE, Colette. The birth of an ideology: myths and symbols of nation in Late-Medieval France. Berkeley: University of California Press, 1991.

BOURIN, Monique; CHERUBINI, Giovanni; PINTO, Giuliano (a cura di). Rivolte urbane e rivolte contadine nell'Europa del Trecento: un confronto. Firenze: Firenze University Press, 2008.

CHEVALIER, Bernard. Les bonnes villes, l'État et la société dans la France de la fin du XV siècle. Orleans: Paradigm, 1995.

Anos 90, Porto Alegre, v. 21, n. 40, p. 333-361, dez. 2014 


\section{Fabiano Fernandes}

COHN Jr., Samuel K. Lust for Liberty: The Politics of Social Revolt in Medieval Europe, 1200-1425. Cambridge: Harvard University Press, 2008.

DERMUGER, Alain. Temps de crises, temps d'espoirs, XIV $\mathrm{E}-X V^{\mathrm{e}}$ siècle. Nouvelles Histoires de La France Mediévale. Paris: Seuil, 1990.

FAVIER, Jean. Paris au XV Siècle, 1380-1500. Paris: Hachete, 1975. p. 124-130.

GIESEY, R. The Royal Funeral ceremony in Renaissance France. Geneve: E. Droz, 1960. GOFFMAN, Erving. A representação do Eu na vida cotidiana. Petrópolis: Vozes, 2009. GUENÉE, Bernard (Ed.). Chronique du Religieux de Saint-Denys. Paris: Éditions des Travaux Historiques et Scientifiques, 3 v, 1994.

GUENÉE, Bernard. L'Opinion publique à la fin du Moyen Age. D'après la "Chronique de Charles VI” du Religieux de Saint-Denis. Paris: Perrin, 2002.

HANLEY, S. M. The Lit de justice of the kings of France: Constitutional ideology in legend, ritual and discourse. Princeton: Princeton University Press, 1983.

JACKSON, R. Vive le Roi! A History of French Coronation from Charles V to Charles X. Chapel Hill: University of California Press, 1984.

MIROT, Leon. Les Insurections Urbaines au début du Régne de Charles VI: Leurs Causes, Leurs Conséquences. Paris: Albert Fontemoing, 1905.

MOLLAT, Michel; WOLFF, Philippe. Ongles bleus, Jacques et Ciompi: Les révolutions populaires en Europe aux XIV et XV siècles. Paris: Calmann-Lévy, 1970. PARTIE INÉDITE DES CHRONIQUES DE SAINT-DENIS. suivie d'un récit également inédit de la campagne de Flandres en 1382 et d'un poème sur les joutes de Saint-Inglebert (1390). Paris: De l'imp. de Ch. Lahure, 1864.

POLLAK, Michael. Memória, esquecimento e silêncio. Revista Estudos Históricos, Rio de Janeiro, v. 2, n. 3, p. 3-15, 1989.

ROSSIAUD, Jacques. Crises et consolidations. In: DUBY, Georges (Dir.). Histoire de la France urbaine: La ville médiévale. Tome 2. Paris: Seuil, 1980. p. 548-574.

SMALL, Graeme. Late Medieval France. NY: Palgrave/Macmillan, 2009.

VAULTIER, Roger. Le Folklore pendant la guerre de cent ans d'après les lettres des rémissions du Trésor des Chartes. Paris: Librairie Guénégaud, 1965.

Recebido em: 28/06/2013

Aprovado em: 01/11/2013 